\title{
Optimization of Coal/biomass Blend Combustion in Circulating Fluidized Bed Reactor Using Novel Aspen Plus Models
}

\author{
Lyazzat Kulmukanova $^{1}$, Dhawal Shah ${ }^{1}$, Yerbol Sarbassov ${ }^{1}$ \\ ${ }^{1}$ The Environment and Resource Efficiency Cluster \\ Department of Chemical and Materials Engineering, School of Engineering, Nazarbayev University \\ Kabanbay batyr ave. 53, block 3, Nur-Sultan city, Kazakhstan \\ lyazzat.kulmukanova@nu.edu.kz; dhawal.shah@nu.edu.kz; ysarbassov@nu.edu.kz
}

\section{Extended Abstract}

Despite active development of alternative energy sources according to climate change regulations, coal demand, led by growth of economy and industrial activity, has increased across the world. Taking even higher shares in countries' energy generation e.g., in Central Europe countries like Poland coal share in energy sector reached 80\%, coal demand will increase, as has also been forecast by International Energy Agency [1,2]. Although combustion of coal is a mature technology, it has significant drawbacks that put this technology under debate. Primarily, the emissions of trace pollutants $\left(\mathrm{SO}_{\mathrm{x}}, \mathrm{NO}_{\mathrm{x}}, \mathrm{CO}\right.$, $\mathrm{CO}_{2}$, etc.), in large amounts contribute to overall air quality deterioration. In addition, combustion process is also notoriously known for its low efficiency, ranging between $37 \%$ and 57\%, partly caused by the quality of coal [3]. Hence, a need for advanced optimization emerges, to minimize emissions and to operate combustion at high efficiencies. Several models of coal combustion processes have been developed; however, the existing models have several constraints in terms of the type of utilized coal, operating conditions, simplification assumptions, and overall stiffness of the model. Moreover, these models have not considered utilization of a blend fuel (coal/biomass) for optimization purposes.

Herein, we develop an advanced Aspen Plus simulation model of coal/biomass blend fuel combustion in fluidized bed and validate the results with a pilot-scale reactor. The results for the composition of the flue gas obtained from both, the simulation and the pilot plant, on combustion of Ekibastuz high-ash coal, exhibit discrepancies of maximum $15 \%$. Contrary to existing literature, the developed simulation also adopts a holistic approach that can incorporate various grades of coal, mixtures of coal with biomass, as well as varying operating conditions. In particular, we have employed the novel FluidBed reactor model, made available in the recent version of Aspen Plus, which can simultaneously include reaction kinetics and bed hydrodynamics in the combustion process. Furthermore, we have accounted for high ash content and accurately mimic the temperature gradient throughout the reactor. In addition, we plan to explore, the behavior of the system in the presence of mixed fuel combustion and in oxygen rich environment.

More accurate results of a coal combustion process would allow to fine-tune the operational and characteristics parameters of the fluidized bed reactor, to improve the combustion efficiency and decrease emissions by adjusting temperature, pressure and oxy-fuel ratio. Preliminary sensitivity analyses for pure low-grade coal combustion have shown that increasing operating temperature by $200^{\circ} \mathrm{C}$ leads to decrease in $\mathrm{CO}$ and $\mathrm{CO}_{2}$ emissions by $75 \%$, along with the possibility to decrease oxygen level in the gas, while maintaining the same efficiency. Declaring coal as non-conventional solid component in Aspen Plus also allows changing proxanal, ultanal, sulfanal values and altering the coal to biomass ratio, simulating the combustion process of coal/biomass blend, which is considered a breakthrough in making coal combustion process more environmentally friendly. In summary, we aim to develop a model for biomass/coal blend fuel, particularly for the local Ekibastuz coal, to identify optimal coal/biomass ratio, along with oxygen/fuel ratio to perform energy, exergy, and economic analysis to optimize the plant operations.

\section{References}

[1] IEA (2019), "Coal 2019", IEA, Paris [Online]. Available: https://www.iea.org/reports/coal-2019

[2] IEA (2019), "Poland 2019", IEA, Paris [Online]. Available: https://www.iea.org/countries/poland

[3] K. Goto, K. Yogo, and T. Higashii, "A review of efficiency penalty in a coal-fired power plant with post-combustion $\mathrm{CO}_{2}$ capture," Applied Energy, vol. 111, pp. 710-720, 2013. 